
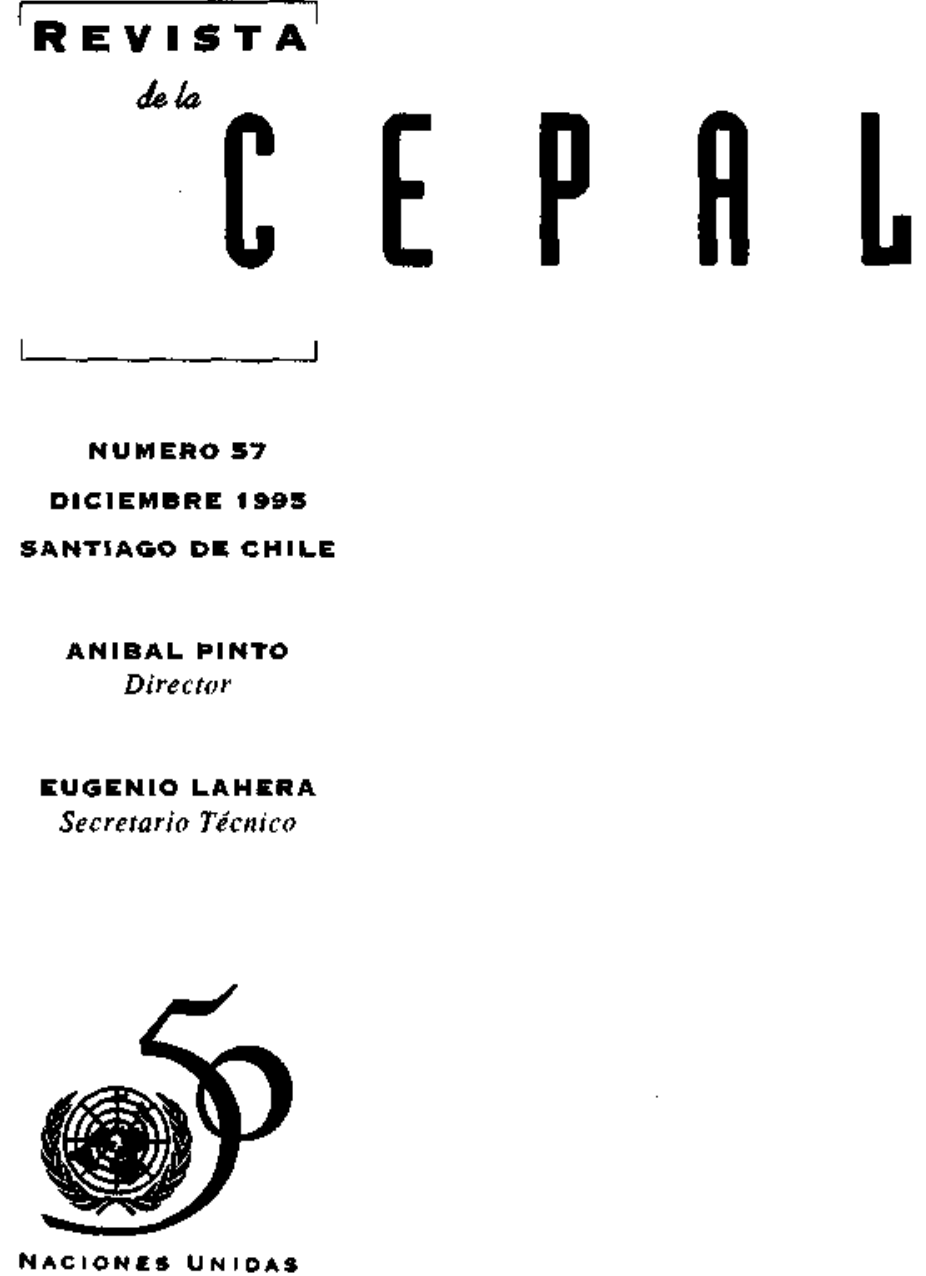
Las Naciones Unidas y la CEPAL en el

Cincuentenario de la Organización

Gert Rosenthal

La creación de las Naciones Unidas y de la CEPAL

Hernán Santa Cruz

Derechos humanos: el caso de los niños

Teresa Albánez

Gobernabilidad, competitividad e integración social

Fernando Calderón

Reforma laboral y equidad social:

la privatización de los puertos

Larry A. Burkhalter

Nuevas tendencias en las políticas salariales

Andrés E. Marinakis

Centroamérica: desempefio macroeconómico y

financiamiento social

Francisco Esquivel

Panamá y la integración económica centroamericana

Luis René Caceres

La dualidad del tipo de cambio en la economía cubana de los noventa

Archibald R.M. Ritter

Transnacionalización e integración productiva en

América Latina

Armando Di Filippo

Indice de autores y de temas en la Revista de la CEPAL, números 1 al 57

Orientaciones para los colaboradores de la Revista de la CEPAL 195 


\title{
Reforma laboral
}

\author{
y equidad social: \\ la privatización \\ de los puertos
}

\section{Larry A. Burkhalter}

Especialista en Transporte

Martimo y Puertos, Unidad de Transporte, División de Comercio Imternacional, Transporte y Financiamiento. CEPAL.
Los gobiernos de la región de la CEPAL han establecido regímenes laborales que respaldan la aspiración de los trabajadores portuarios a un salario estable y un empleo seguro, los aíslan de las señales del mercado y originan monopolios de manipulación de la carga. Con el advenimiento de una economía globalizada, la introducción de políticas de crecimiento basado en las exportaciones, la adquisición de equipos de manipulación de carga y sistemas de información electrónicos modernos y la participación de intereses privados en la oferta de servicios portuarios, las empresas pueden comparar, adquirir y emplear materias primas, mano de obra e insumos de todo el mundo, lo cual ha transformado el concepto tradicional de competencia; ya no se trata de una pugna entre productos terminados comparables sino que abarca desde los insumos hasta el producto final. La mano de obra portuaria es sólo uno de los insumos de los procesos de distribución y debe estructurarse comercialmente para permitir la competencia con otros puertos del mundo. El libre juego de los mecanismos del mercado ofrece un parámetro externo para controlar el tamaño de la fuerza laboral, armonizar los deseos de estibadores y empresarios del transporte marítimo e impulsar a cada uno a aumentar gradualmente la productividad, reducir costos, innovar y hacer las inversiones necesarias. En la reforma de los regímenes laborales portuarios se debería eliminar los impedimentos reguladores al libre juego de los mecanismos del mercado; descentralizar y liberalizar el mercado laboral; utilizar leyes antimonopolios aplicables a sindicatos y empresarios del transporte marítimo para evitar el uso indebido de los mecanismos del mercado; eliminar la injerencia directa del gobierno en las operaciones portuarias, las negociaciones colectivas y los arreglos informales de conflictos, y fomentar la equidad social orientada hacia la oportunidad al conceder prestaciones a los trabajadores. Con un régimen laboral portuario de enfoque comercial, los empresarios del transporte marítimo acabarían por admitir que sus objetivos comerciales y las metas sociales de los estibadores están interrelacionados y no pueden alcanzarse en forma independiente. 


\section{I}

\section{Antecedentes}

Durante muchos siglos, la carga y descarga de buques y el consiguiente almacenamiento de las mercaderías eran faenas que realizaban trabajadores ocasionales, de manera informal y en un ambiente extremadamente peligroso e insalubre. El único requisito para contratar a esos hombres era su fortaleza y no se tomaban en cuenta sus aptitudes ni su capacidad para resolver problemas. No necesitaban entrenamiento, y se los podía reemplazar fácilmente si se cansaban, no podían trabajar, no querían correr riesgos o estaban lesionados o enfermos. Estas condiciones sentaron las bases para que durante siglos se creyera que el trabajo portuario era sólo para los que no podían encontrar empleo en otra parte. Los estibadores reaccionaron ante los abusos que caracterizaban a sus empleos y a los equipos de manipulación de carga que desplazaban a la mano de obra, organizando sociedades de asistencia mutua que luego se transformarían en poderosos sindicatos. Estos factores, sumados a la Gran Depresión de los años treinta, favorecieron la convicción muy generalizada de que la injerencia sistemática del gobierno era esencial para la estabilidad económica, el pleno empleo y la equidad social. En consecuencia, los gobiernos de la región de la CEPAL adoptaron regímenes laborales paternalistas, muchos de los cuales aún siguen vigentes (Segura, 1993, pp. 32, 33 y 36; Edwards, 1993, p. 13; Banuri, 1990, pp. 51-61).

Los regímenes laborales paternalistas favorecen decididamente las metas sociales de los estibadores, hacen menos propicio el clima para las inversiones de los intereses privados y han llevado a los gobiernos a expandir su papel de reguladores a propietarios, inversionistas, empleadores y administradores. Estos regímenes se han basado en ciertos supuestos, como los siguientes: el capital y la mano de obra están enfrentados en un conflicto irreconciliable y destructivo; los servicios prestados por los monopolios de manipulación de carga pueden ser tan eficaces en función de los costos como los que presta el sector privado; no es necesario que los gobiernos ni los trabajadores portuarios respondan a las señales del mercado; Ias tecnologías que ahorran mano de obra constituyen una falta de responsabilidad social; los estibadores sólo se esforzarán por aumentar la productividad y reducir los costos si se les ofrecen incentivos monetarios; los costos sociales de la reforma laboral portuaria son tan altos que los gobiernos no pueden incorporar los mecanismos del mercado en los regímenes laborales a fin de lograr un equilibrio de índole comercial entre los intereses de exportadores, importadores, transportistas, estibadores y empresarios del transporte marítimo; y la existencia de monopolios de mano de obra portuaria, alianzas políticas y subvenciones estatales no redundará en servicios portuarios con exceso de personal, caros e ineficientes (Apolo, 1994, pp 47, 57-59; Couper, 1986, p. 55). ${ }^{1}$

Estos supuestos han perdido vigencia con la aparición de la economía globalizada, las políticas de crecimiento basado en las exportaciones y la participación privada en los puertos estatales. Por ejemplo, ya no se puede considerar el capital y la mano de obra en términos de medios y fines y, por consiguiente, en un conflicto irreconciliable y destructivo, ya que constituyen dos caras de la misma moneda. Ambos son medios y fines, y sólo pueden alcanzarse en un entorno sujeto a los mecanismos del mercado, dado que tales mecanismos ofrecen los únicos parámetros comunes e invariablemente imparciales mediante los cuales pueden conjugarse los objetivos comerciales y las metas sociales del capital y la mano de obra. Asimismo, las inversiones en tecnología que ahorra mano de obra han pasado a tener responsabilidad desde el punto de vista social, ya que las mejoras en productividad y eficacia en función de los costos hacen que el puerto resulte más atractivo para los usuarios, generan nuevas fuentes de empleo en la zona de influencia del puerto y crean un entorno laboral más seguro para los estibadores. Los objetivos comerciales de ex-

\footnotetext{
I Como ejemplo reciente del exceso de personal, en un conflicto entre la International Longshoremen's and Warehousemen's Union (ILWU) --Unión Internacional de Estibadores y Almacenadores--, que representa a los trabajadores portuarios de la costa oeste de los Estados Unidos, y el Terminal de Cereales Peavey por el despido de trabajadores superfluos, el tribunal dictaminó que las pruebas revelaban que, durante varios años, las funciones del sobrecargo (el empleado que revisa la carga) habían sido similares a las que desempeñaba el jefe de cargas (el estibador más experimentado). De este modo, con frecuencia la oferta de mano de obra portuaria y su asignación no tienen relación alguna con los volúmerwes de la carga que se está movilizando ni con el equipo de manipulación utilizado (véanse Mongelluzzo, 1994, p. 8B, y Davies, 1993a, p. 5B).
} 
portadores, importadores, transportistas y empresarios del transporte marítimo, y las metas sociales de la mano de obra portuaria han pasado a ser complementarios e interdependientes, y no pueden lograrse sin un esfuerzo colectivo de colaboración.

En una economía globalizada altamente competitiva, la equidad social es comercial y se orienta hacia la oportunidad. Ya no se ajusta a los parámetros de otrora paternalistas y burocráticos, que distorsionaban el mercado, sencillamente porque no garantizaría puestos de trabajo ni un nivel determinado de ingresos, prestaciones y poder adquisitivo a los estibadores (Apolo, 1994, pp. 40-41). Sin embargo, debería ofrecerles programas de capacitación y rea- diestramiento, la asignación de nuevos puestos de trabajo para que pudieran reincorporarse con rapidez en la fuerza laboral nacional, pagos por jubilación anticipada, indemnizaciones justas por renunciar a prerrogativas y derechos adquiridos y un marco institucional que asegure que ningún otro grupo de la comunidad portuaria o comercial se apropiará de las prestaciones y privilegios que ellos han cedido. Las metas de la equidad social orientada a la oportunidad son las de crear una fuerza de trabajo portuaria dinámica, calificada y bien remunerada, y permitir que los puertos funcionen como entidades comerciales sin protección, en un entorno mundialmente competitivo.

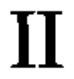

\section{Mandatos comerciales}

Durante la era paternalista se institucionalizaron muchas prácticas de trabajo portuario como los monopolios de manipulación de carga y las ineficientes operaciones de dos turnos. Para las naciones que adoptaron políticas de crecimiento basado en las exportaciones, esos costos e ineficiencias tienen un impacto negativo en los precios de exportaciones e importaciones. Los estibadores se enfrentan a un entorno comercial abierto en que el costo y la productividad de sus servicios compiten no sólo con los puertos vecinos que abastecen la misma zona de influencia, sino también con los que están del otro lado del océano y manipulan bienes parecidos destinados a los mismos mercados. Un ejemplo de este fenómeno es la competencia que hay entre las redes de distribución de fruta fresca de Argentina, Chile, Nueva Zelandia y Sudáfrica a compradores de Chicago (Estados Unidos); si los costos de mano de obra portuaria son excesivos o la productividad es baja, para cualquiera de ellos podría significar la pérdida de ese mercado, aunque sus costos de cultivo y cosecha fueran inferiores. Así, el concepto tradicional de competencia entre productos terminados comparables se ha transformado en una competencia desde el insumo hasta el producto final, en que cada insumo y cada producto terminado tiene sus propias y elevadas exigencias de mercado.

\section{El mercado laboral portuario}

Los sindicatos han logrado dominar los puertos de la región de la CEPAL durante muchos decenios gracias al control que ejercen sobre la oferta de mano de obra mediante medidas políticas como sistemas de registro, monopolios de manipulación y almacenamiento de carga, y subvenciones estatales. La capacidad de comparar los costos de todos los factores de producción, desde la materia prima hasta la mano de obra y desde los productos terminados hasta los servicios de transporte terrestre, crea un poderoso incentivo para acabar con el aislamiento de los estibadores de las exigencias competitivas del mercado Iaboral internacional y aumentar la productividad y reducir los costos, lo que era inconcebible hace apenas un decenio. Sin embargo, los registros, monopolios y subvenciones se han obtenido merced a alianzas políticas entre sindicatos, administraciones portuarias y gobiernos centrales y restringen la oferta de mano de obra, garantizan la seguridad en el empleo y brindan muchos beneficios que no son de mercado.

Los exportadores, importadores y transportistas eran tildados de antipatrióticos si criticaban o reprobaban los costos portuarios excesivos y las ineficiencias innecesarias y, en consecuencia, solían asumir una postura pasiva, casi impropia de empresarios. Las administraciones portuarias, en su calidad de empresarios del transporte marítimo, adoptaban un criterio social en el desempeño de sus funciones, con el fin de evitar un descrédito semejante. En las economías basadas en las exportaciones, los registros, monopolios y subvenciones tan solo señalan ineficiencias que deben eliminarse para aumentar la competitividad de 
los bienes de una nación en los exigentes mercados internacionales y la seguridad en el empleo de la mano de obra portuaria. La mejor manera de regular la oferta de estibadores, así como sus salarios y prestaciones, es mediante las necesidades de los exportadores, importadores y transportistas, que es otra forma de decir que la mano de obra portuaria debe estar expuesta a los mecanismos del mercado.

El movimiento laboral portuario ha utilizado su posición estratégica en los puertos para presionar a los gobiernos a fin de que adopten medidas políticas que amortigüen el impacto de los factores exógenos (el entomo competitivo al que se enfrentan los exportadores, importadores y transportistas, y los sistemas de transporte de que disponen los dueños de las cargas) y endógenos (productividad y costo-eficacia de los servicios de almacenamiento y manipulación de carga) sobre la demanda de mano de obra portuaria. Sin embargo, la introducción de políticas de crecimiento basado en las exportaciones demuestra que la demanda de los servicios de estibadores proviene de la demanda y competitividad de los bienes que manipulan, de manera que los gobiernos no pueden seguir eludiendo esa realidad aislándolos de los mecanismos del mercado. ${ }^{2}$ Tanto el sistema favorecido por el sindicato como el preferido por los empleadores para controlar la demanda de mano de obra portuaria crean prerrogativas y prestaciones onerosas y hacen caso omiso de la realidad comercial de la competencia que enfrentan exportadores, importadores y transportistas. En lugar de tomar medidas para estabilizar la demanda de trabajadores portuarios, quizá sería más útil estabilizar sus salarios, reteniendo fondos suficientes de sus ingresos para pagarles salarios durante los períodos en que habitualmente no hay empleo, y estableciendo una clase especial de trabajadores estacionales.

\section{La resolución de conflictos laborales}

Se calcula que los costos indirectos de resolver los conflictos laborales en los tribunales son 100 veces mayores que los costos directos de los laudos de los jurados, los arreglos de controversias y los honorarios de los abogados (Edwards, 1993, p. 193). Evidentemente, la resolución informal de los conflictos laborales portuarios entre las partes es más aceptable

\footnotetext{
2 La Conferencia de las Naciones Unidas sobre Comercio y Desamollo (UNCTAD, 1993, p. 2) señala que la demanda de servicios portuarios que registran estos mercados (especificos) proviene de una demanda de servicios de logística de puerta a puerta, que a su vez se deriva de la demanda de transporte de los productos.
}

y modificable que la que impone un árbitro o juez (Schwieger, 1988, pp. 344-349). La resolución de conflictos entre la mano de obra portuaria y los empresarios del transporte marítimo debería empezar con un estudio del problema por un comité conjunto obreropatronal. ${ }^{3} \mathrm{~A}$ modo de aliciente adicional para utilizar procedimientos informales, debería permitirse que los exportadores, importadores y transportistas que pudieran demostrar que sus finanzas se vieron perjudicadas entre el momento en que se abandonaron los procesos del comité y se escuchó la decisión final en un procedimiento jurídico o arbitral cobraran una indemnización por daños y perjuicios que las partes sufragarian por partes iguales. La resolución informal de los conflictos laborales se transformaría en un componente de valor agregado de los servicios portuarios, porque los costos de los cierres patronales y de las huelgas o del trabajo a ritmo lento recaerían en los propios litigantes.

El derecho a la huelga fue utilizado profusamente por la mano de obra portuaria durante la era paternalista, cuando había pocas fuentes alternativas de productos y pocos sustitutos de los artículos deseados, y las interrupciones del comercio eran un fenomeno habitual. La economía globalizada, las políticas de crecimiento basado en las exportaciones, los equipos de manipulación de carga que hacen uso intensivo de capital y la participación privada en los puertos estatales han transformado a los estibadores y los empresarios del transporte marítimo en socios de una empresa conjunta con los usuarios del puerto, vale decir, exportadores, importadores y transportistas; la interrupción de las operaciones de manipulación de la carga perjudica a todos, y la resolución de los conflictos exige los mejores esfuerzos, la confianza mutua y la buena voluntad de cada uno para mantener un ambiente de constante colaboración (Di Benedetto, 1994, p. 1B; Cantwell, 1994, p. 7B; Davidow y Malone, 1992, p. 205; Cabot, 1986, pp. 112-127). El derecho a huelga intensifica el disputado mercado que deben enfrentar los empresarios, ya que hay un gran número de posibles ingresantes que desearían satisfacer las necesidades de los usuarios, de manera que ese derecho debe utilizarse de forma tal que permita que los estibadores obtengan los salarios y prestaciones deseados, salvaguardando al mismo tiempo la viabilidad comercial de los usuarios y empresarios del transporte marítimo.

\footnotetext{
3 Véase, por ejemplo, Compañía Guatemalteca de Terminales a Granel. S.A., 1988, pp. 28-30.
} 


\section{La segurldad en el empleo}

Los reglamentos que prohiben despedir a los estibadores reducen considerablemente su disposición a aceptar propuestas de reestructuración del trabajo, atender a las necesidades de servicio de los usuarios y utilizar nuevas tecnologías. Para que los estibadores tengan seguridad en sus empleos, los gobiernos deben adoptar regímenes laborales portuarios que utilicen los mecanismos del mercado a fin de lograr un equilibrio comercial entre las metas sociales de la mano de obra portuaria y los objetivos comerciales de los empresarios del transporte marítimo, además de aislar a los gobiernos de las presiones políticas de ambos grupos. Una reforma de los regímenes laborales orientada hacia el mercado entraña aceptar la participación privada en los servicios portuarios, pero no equivale a volver a las prácticas del empleo día a día y faena por faena controlado por los empleadores. Las presiones competitivas de una economía globalizada exigen que las disposiciones de seguridad en el empleo también protejan la viabilidad comercial de los empleadores. En un entorno portuario abierto y competitivo, los estibadores acabarán por aceptar que la seguridad en el empleo depende del éxito de los usuarios y los empresarios del transporte marítimo, no de garantías constitucionales y reglamentarias.

Los estibadores que pierden su empleo como resultado de los esfuerzos por responder a la economía globalizada mediante la participación del sector privado y la utilización de tecnologías que ahorran mano de obra pueden reinsertarse más fácilmente en la fuerza de trabajo nacional si los cursos de capacitación se complementan con servicios de colocaciones y están sufragados conjuntamente por los empresarios del transporte marítimo, los gobiernos y los trabajadores desplazados. Estos últimos podrían destinar para este fin parte de los pagos que reciben por concepto de solución de litigios e indemnizaciones. Dichas tecnologías también han modificado los requisitos de calificaciones que se piden a los estibadores; de operadores que desempeñaban actividades unifuncionales se ha pasado a necesitar una fuerza de trabajo de habilidades múltiples que opere y mantenga complejos equipos que incorporan un gran número de funciones distintas. Los programas de capacitación deben entregar a los trabajadores portuarios que queden los conocimientos necesarios para entender cómo la mayor productividad mejora la competitividad de las exportaciones en los mercados intemacionales, y cómo esa competitividad atrae a exportadores, importadores y transportistas y genera nuevas oportunidades de empleo dentro del puerto y fuera de él. ${ }^{4}$ En el puerto de Tilbury (Londres), por ejemplo, los estibadores visitan las instalaciones de exportadores e importadores para observar cuán oneroso e inconveniente resulta para ellos que las mercaderías sufran daños, robos o demoras (Finney, 1993, p. 4).

\section{III}

\section{Mandatos operacionales}

Los gobiemos y los sindicatos tienen mucho en común. Ambos son instituciones sociopolíticas que afectan enormemente a las metas comerciales de los usuarios. Habida cuenta de que los gobiernos actúan como propietarios y operadores de los puertos, empleadores de la mano de obra portuaria y participantes directos en las negociaciones colectivas, los sindicatos cuentan con un aliado fácilmente accesible, dado que tales negociaciones son bipartitas (gobierno-trabajadores), no tripartitas (gobierno-trabajadores-empleadores). Habitualmente surgen conflictos porque los usuarios exigen que los gobiernos (administraciones portuarias y empresarios del transporte marítimo) obliguen a los estibadores a aceptar tecnologías y arreglos ins- titucionales modemos que aumenten la productividad y reduzcan los costos. Los sindicatos piden que los gobiernos (administraciones portuarias y empresarios del transporte marítimo) protejan sus salarios, prestaciones y fuentes de trabajo. Para resolver los conflictos, los gobiernos (ministerios del trabajo) intervienen y en general deciden que no se comprará el equipo o, si la compra es inevitable, que se lo utilizará aplicando prácticas de uso intensivo de mano de obra. En este contexto, los trabajadores portuarios suelen no

4 Fairplay. The International Shipping Weekly, 1994, p. 8. Respecto a una situación similar en la industria británica del carbón, vease The Economist, 1993a, pp. 39 y 40. 
responder a la competencia mundial y a las metas de crecimiento basado en las exportaciones, y rechazan las peticiones de los usuarios de adquirir equipos modernos, aumentar la productividad, reducir los costos y utilizar delimitaciones flexibles de funciones.

\section{Las necesidades de los usuarios del puerto}

En un mundo comercial altamente competitivo, regido por las leyes del mercado, los sindicatos portuarios acabarán por empobrecerse a sí mismos y a los usuarios si hacen caso omiso de las necesidades de estos últimos. Las negociaciones colectivas tienen muy poco que ver con el aumento de la productividad y la eficacia en función de los costos. Lo que ocurre con más frecuencia es que los gobiernos (administraciones portuarias) sucumben a las demandas de los sindicatos portuarios y no intentan determinar ni satisfacer las necesidades comerciales de los usuarios, en tanto que los gobjernos (ministerios del trabajo) sencillamente piden subvenciones más cuantiosas de los gobiernos (departamentos del tesoro) para sufragar mayores gastos. Esta espiral del aumento de los costos se quebró con la aparición de la economía globalizada, la introducción de las políticas de crecimiento basado en las exportaciones, la participación de intereses privados en los puertos estatales y la utilización de tecnologías avanzadas. Los estibadores fueron aislados de la competencia porque los gobjernos consideraban que los puertos tenían un papel estratégico en la defensa nacional y la seguridad económica, pero actualmente tanto los puertos como los trabajadores portuarios están saliendo de esa ecuación política y forman parte de un mercado globalizado en que las necesidades de los usuarios son de importancia capital.

Los usuarios del puerto requieren mejoras progresivas de la productividad y costo-eficacia en los servicios de manipulación y almacenamiento de la carga a fin de aumentar la competitividad de sus bienes y servicios en los mercados internacionales. La mayor parte de estas mejoras son producto de tecnologías avanzadas y mecanismos institucionales modernos que pueden volver superfluas ciertas calificaciones y tareas. El movimiento laboral portuario ya no puede utilizar sus alianzas políticas y amenazas de disturbios civiles para preservar una demanda histórica de los servicios de los estibadores y asegurar que las calificaciones exigidas sigan siendo prácticamente las mismas. La velocidad con que los regímenes laborales, los acuerdos colectivos y las prácticas de trabajo en el puerto permiten que los estibadores res- pondan de manera competitiva a las señales del mercado es la clave del éxito comercial en un mercado globalizado. Las garantías de seguridad en el empleo e ingresos para la mano de obra portuaria no pueden hacer atractivos a los puertos, aun como entidades sociales, a menos que aumenten la viabilidad comercial de los usuarios en los mercados mundiales.

\section{Participación de los estibadores}

Los conocimientos, la experiencia y la inteligencia de los que efectivamente prestan servicios de manipulación y almacenamiento de la carga son un recurso que puede contribuir enormemente a los ingresos y la competitividad de los puertos y los operadores de los terminales privados, pero a menudo es considerado por los empresarios del transporte marítimo como una usurpación de sus prerrogativas de mando y por los dirigentes laborales portuarios como un intento de socavar la solidaridad del movimiento sindical (OIT, 1981, pp. 29-35). Se suele afirmar que las prerrogativas de mando se derivan del principio de propiedad; por ende, los estibadores sólo tendrán ese poder si también son propietarios. Asimismo, se sostiene que la participación de los estibadores en las utilidades y en las decisiones de la dirección es una consecuencia natural de que los trabajadores inviertan su trabajo, como otras personas invierten capital, en una empresa (OIT, 1981, pp. 14 y 20). Cada uno de estos argumentos procura justificar la participación de los estibadores en las utilidades y en las decisiones relativas al lugar de trabajo atendiendo a un atributo inicial (propiedad o inversión), pero su base no radica en silogismo ni argumento circular alguno. Por el contrario, radica en comprender que los estibadores tienen un bagaje de experiencia útil que puede aprovecharse para mejorar la productividad, reducir los costos, aumentar las ganancias de los usuarios y los empresarios del transporte marítimo y satisfacer sus propias metas sociales orientadas hacia la oportunidad.

\section{Tecnologias modemas y capacitación de los estibadores}

Para que los estibadores presten servicios adecuados a los usuarios, aumenten la competitividad de las exportaciones en los mercados mundiales y conserven sus propios puestos, se ha vuelto imperativo que respondan a las señales del mercado, utilicen tecnologías avanzadas y acepten programas de capacitación. Estos cambios producen una situación estresante para 
los trabajadores portuarios. Para propiciar su aceptacion, se les debe ofrecer como contrapeso una respuesta humana, que anteriormente ha sido mencionada como equidad social orientada hacia la oportunidad. Las principales limitaciones para la adquisición de nuevos conocimientos probablemente estén dadas por la capacidad que cada persona tiene para asumir mayores responsabilidades y exigencias en su trabajo. Los sindicatos tenían considerable fuerza cuando la mano de obra portuaria era una masa indiferenciada de personas necesitadas de representación, pero hoy un grupo mucho menor de trabajadores altamente calificados realiza las mismas operaciones con equipos muy sofisticados. Este fenómeno puede debilitar el movimiento sindical portuario si los estibadores rechazan nuevas tecnologías y no están dispuestos a negociar acuerdos colectivos que permitan su utilización eficiente. Las tecnologías modernas permiten ampliar las habilidades y conocimientos de los esti- badores, de saber hacer funcionar una máquina a comprender todas las operaciones portuarias, y luego a tomar conciencia de cómo encajan los servicios portuarios en una perspectiva más vasta de las necesidades comerciales.

A modo de ilustración del descenso de la demanda de estibadores como resultado de las tecnologías modernas, basta decir que para movilizar carga seca a granel en los puertos del Reino Unido a principios del decenio de 1950 hacían falta 20 hombres para cada una de las bodegas de un buque. Hoy la carga de cereales es responsabilidad de tres hombres, aunque la tecnología que se utiliza permite que uno solo ejecute todas las operaciones (Davies, 1993b, p. 8B; y The Journal of Commerce, 1993a, p. 1B). Con respecto a los contenedores marinos, el cuadro 1 muestra la experiencia de los sistemas de manipulación de carga por contenedores en los puertos de la costa oeste de los Estados Unidos.

CUADRO 1

Estados Unidos (puertos de la costa oeste): Efecto de los contenedores en la productividad de los estibadores

\begin{tabular}{cccc}
\hline Afio & $\begin{array}{c}\text { Horas-hombre trabajadas } \\
\text { (millones) }\end{array}$ & $\begin{array}{c}\text { Toneladas de carga manipuladas } \\
\text { (millones) }\end{array}$ & $\begin{array}{c}\text { Productividad } \\
\text { (toneladas/horas-hombre) }\end{array}$ \\
\hline 1960 & 29.1 & 28.5 & 0.98 \\
1980 & 18.5 & 113.7 & 6.15 \\
1987 & 17.1 & 157.8 & 9.23 \\
1993 & 15.7 & 183.6 & 11.69 \\
1994 & 17.0 & 199.0 & 11.71 \\
\hline
\end{tabular}

Fuente: Asociación Marítima del Pacifico.

Como se aprecia en el cuadro, gracias a los sistemas de manipulación de carga por contenedores, entre 1960 y 1994 fue posible reducir $41.6 \%$ (de 29.1 a 17.0) las horas-hombre de estibadores necesarias, pese a que los volúmenes de la carga aumentaron 6.98 veces (de 28.5 a 199 ).

\section{La eficiencia}

El concepto de eficiencia habitualmente se define en términos vagos, como la satisfacción de necesidades dentro de limitaciones tecnológicas y de recursos (Eatwell, Milgate y Newman (eds.), 1987, pp. 107 y 108). Para los efectos de este trabajo, la eficiencia del puerto se refiere a la prestación de servicios de manipulación y almacenamiento de la carga que satisfagan las necesidades de los usuarios de la manera más pro- ductiva y eficaz posible en función de los costos. Esto sugiere que los progresos en salarios y prestaciones de los estibadores se podrían considerar eficientes si están basados en aumentos de la productividad y no restringen $o$ afectan negativamente las actividades comerciales de usuarios y empresarios del transporte marítimo. Dicho de otra manera, la eficiencia portuaria depende de la competencia de precios entre los empresarios del transporte marítimo y de la competencia de productividad entre los estibadores. Los gobiernos pueden contribuir a aumentar la eficiencia portuaria formulando un marco institucional que permita el libre juego de los mecanismos del mercado para balancear sus propios intereses, las metas sociales de la mano de obra y los objetivos comerciales de los usuarios.

Para ilustrar este punto, la International 
Longshoremen's Association (ILA) - Asociación Internacional de Estibadores- del puerto de Filadelfia, en la costa este de los Estados Unidos, ha accedido a utilizar menos estibadores en turnos de nueve horas sin pago adicional alguno al descargar buques que transporten fruta chilena, $y$ ha formulado un plan para continuar dichas operaciones durante los conflictos laborales, de modo que los expedidores no utilicen otros puertos (The Journal of Commerce, 1993b, p. 1B, América Economía, 1993, p. 36; Di Benedetto, 1991, p. 8B; Knox, 1991, pp. 1B y 8B; Benedict, 1990 , pp. 28 y 29). Sin embargo, el puerto ha estado perdiendo cargas de fruta chilena frente al puerto vecino de Wilmington (Delaware), donde las tarifas son 40\% menores, aunque los estibadores pertenecen al mismo sindicato (Monk, 1995, p. 10B; Holcomb, 1994b, p. 7B; The Joumal of Commerce, 1993c, p. 1B; Holcomb, 1993b, p. 5B; Johnston, 1993, p. 8B; Fair. play. The International Shipping Weekly, 1993, p. 27). Ante esta competencia, los trabajadores de la ILA del puerto de Filadelfia reaccionaron aceptando una reducción de sus salarios desde 21 dólares a 18.50 dólares la hora para cargas fraccionadas, y a 16.50 dólares la hora para la fruta chilena. Por su parte, un sindicato de transportistas de carretera, el de los Teamsters, realiza el mismo trabajo por sólo 11 dólares la hora. ${ }^{5}$ Así pues, en la medida en que los estibadores estén expuestos a la competencia interportuaria, intraportuaria, intersindical, intrasindical y extrasindical, habrá más probabilidades de que se atiendan adecuadamente las necesidades de eficiencia de los usuarios.

Los dirigentes sindicales portuarios suelen decir que los salarios de los estibadores son insignificantes y no les alcanzan para satisfacer sus necesidades básicas, mientras que los usuarios y los empresarios del transporte marítimo disienten, al declarar que superan con creces los de otras regiones. Ambas afirmaciones son ciertas. Ello parecería insinuar que no se ha logrado una asignación eficiente de los recursos porque los costos portuarios y de mano de obra no responden a las señales del mercado. Por ejemplo, los trabajadores del puerto del Callao (Perú) hicieron importantes concesiones respecto de su remuneración. El error más grave fue que la reducción de los salarios de los estibadores no se supeditó a la influencia competitiva de los mecanismos del mercado. Por el contrario, se permitió que la reducción salarial cayera en manos de los agentes marítimos, manteniendo así la misma estructura de costos que exigía que las tarifas portuarias y de los fletes marítimos no sufrieran cambios. Una vez que esas ventajas obtenidas por medios políticos se liberan del control de un grupo determinado, deben someterse a las presiones competitivas y abiertas del mercado. Así se garantizará que el efecto del libre juego de los mecanismos del mercado sobre las concesiones y derechos cedidos contribuya a mejorar progresivamente la eficiencia del puerto.

\section{IV}

\section{Mandatos institucionales}

$\mathrm{El}$ antiguo procedimiento con arreglo al cual el maestro y sus aprendices asumían la responsabilidad por el costo y la calidad de los bienes llegó a su término con la producción masiva de bienes estandarizados a raíz de la revolución industrial. Este hecho permitió que los empleadores se reservaran para sí todas las decisiones, en tanto que la fuerza de trabajo debía seguir sus instrucciones. Sin embargo, con el advenimiento de las fuentes de insumos y fabricación a escala mundial, los procesos de producción automatiza-

s Holcomb, 1993a, p. 5B, y 1994b, p. 1B; Abrams, 1994a, pp. 3C y 4 C y 1994b, p. 8B. Sobre la competencia intersindical en los puertos de la costa ceste de los Estados Unidos, véase Mongelluzzo, 1995, p. 1B. dos, los sistemas electrónicos de información y la competencia de una economía mundial sin fronteras, los trabajadores han completado el ciclo y regresado al punto de partida inicial: la responsabilidad individual por el costo y la calidad de los bienes y servicios. Una reforma del marco institucional para la mano de obra portuaria que refleje estos cambios no significa que los estibadores se verán privados de cualesquiera de sus derechos tradicionales, sino que tales derechos no serán superiores ni inferiores a los de los usuarios y empresarios del transporte marítimo. En resumidas cuentas, el problema principal para la reformulación del marco institucional para la mano de obra portuaria consiste en que el movimiento sindical 
carece de visión cuando se trata de determinar y definir las funciones apropiadas para sus miembros en un entorno comercial que no permite la existencia de sistemas de registro, monopolios de manipulación de carga y subvenciones estatales.

\section{Los mecanismos del mercado}

Los mecanismos del mercado —oferta y demanda, utilidades y pérdidas, economías de escala, preferencias y aversiones de los clientes y la amenaza de quiebra - ofrecen un parámetro externo para controlar el tamaño de la fuerza de trabajo, lo que equilibra el anhelo de los estibadores y empresarios del transporte marítimo de contar con prerrogativas monopolísticas y obliga a ambas partes a aumentar progresivamente la productividad, disminuir costos, innovar y realizar las inversiones necesarias. La compra de insumos y la producción a escala mundial son el resultado del surgimiento de una economía globalizada y la introducción de políticas de crecimiento impulsado por un mercado abierto, y representan una separación de las funciones de producción y consumo en el plano nacional. La producción en serie se basa en el consumo masivo. Anteriormente la prosperidad de los fabricantes estaba ligada a la de sus trabajadores. Actualmente, sin embargo, las empresas combinan insumos materiales, mano de obra y capital de numerosas naciones y venden sus productos en otros países (Handy, 1994 , pp. 200 y 201 ; Reich, 1992 , pp. $110-118$ y 263-265; Marshall y Tucker, 1992, pp. 32 y 33; Porter, 1991, pp. 14 y 15). Se aseguran de que sus productos sean competitivos en mercados internacionales muy exigentes controlando el costo de cada insumo y manteniendo una elevada productividad, factores que influyen directamente en la seguridad en el empleo y en la remuneración del trabajo.

Las realidades múltiples de los puertos -en los aspectos político, social, comercial, técnico, funcional, jurídico y ambiental- son inevitables, pero la importancia atribuida a cada una de ellas y su relevancia serán distintas en una economía globalizada. Ya no es posible aislar a los estibadores de la competencia a que hacen frente los usuarios y empresarios del transporte marítimo, ni del riesgo de quiebra que corren. Tales dificultades sólo pueden enfrentarse exponiendo a los estibadores a la influencia competitiva de los mecanismos del mercado. Los gobiernos deben liberalizar el mercado laboral portuario a fin de eliminar los obstáculos regulatorios que se oponen al libre juego de los mecanismos del mercado sobre la oferta y la demanda, y descentralizar las negociaciones colectivas para asegurar que se sometan a las influencias comerciales de los mercados locales. El objetivo esencial de la reforma laboral portuaria apunta a aumentar el atractivo de los puertos para los usuarios y la competitividad de los bienes manipulados en los mercados internacionales, creando al mismo tiempo una base sociocomercial para que los estibadores obtengan sus salarios y prestaciones. AJ someter a los trabajadores portuarios a la influencia de los mecanismos del mercado, se darán cuenta de que su futuro no reside en la generosidad de los gobiernos sino en satisfacer las necesidades de los usuarios.

\section{Los gobiernos}

Los gobiernos constituyen una forma de contrato sociopolítico entre los funcionarios elegidos y los ciudadanos, en que los primeros escuchan y reaccionan ante los grupos más poderosos y mejor organizados de estos últimos. Los sindicatos son una fuerza dominante en cuestiones portuarias y sus alianzas con funcionarios públicos elegidos y designados y con partidos políticos otorgan a los dirigentes sindicales una influencia considerable en los procesos legislativos, normativos y decisorios. Los monopolios de la fuerza laboral portuaria, los sistemas de registro y las subvenciones en la región de la CEPAL fueron creados por acción y omisión durante muchos decenios por gobiernos de todo el espectro político. Los gobiernos deben superar su arraigada tendencia a resolver los problemas comerciales recurriendo a medios políti$\cos$, a suponer que las políticas y leyes nacionales son superiores a los mecanismos del mercado y a utilizar la fuerza laboral portuaria como instrumento político. Ya no pueden seguir aislando a los estibadores de las exigencias competitivas del mercado laboral internacional, porque las políticas de crecimiento impulsado por las exportaciones los han lanzado a la economía mundial; ya no pueden seguir dedicándose a actividades comerciales, a menos que estén motivados por las utilidades y posean las aptitudes requeridas; ya no pueden continuar empleando a estibadores sobre la base de arreglos burocráticos que los desincentivan.

El objetivo primordial de los gobiernos al reestructurar el marco institucional que rige el trabajo portuario consiste en crear un entomo orientado hacia el mercado en que las personas y los grupos que necesitan cooperar entre sí, pese a intereses contradictorios o incompatibles, utilicen el parámetro externo común de los mecanismos del mercado para forjar acuerdos ve- 
rosímiles y practicables. Para alcanzar tal objetivo, los empresarios del transporte marítimo deben estar en condiciones de responder a las señales del mercado, la fuerza laboral portuaria debe tener acceso a la información administrativa y derecho a participar en las decisiones concernientes al lugar de trabajo, y ambos necesitan estar libres de la influencia de grupos ajenos a los trabajadores y a la dirección de la empresa para negociar acuerdos colectivos. El empeño de los gobiemos por crear una estructura laboral comercial para los puertos sólo tendrá éxito si los propios gobiernos se abstienen de participar directamente en las relaciones laborales. Esto no afectará a sus responsabilidades de formular un marco institucional sensible al mercado que esboce las exigencias en materia de seguridad en el lugar de trabajo, salario mínimo, solución de conflictos, indemnización para trabajadores desplazados y capacitación (Ruiz-Tagle, 1991, pp. 99-124).

\section{Los regímenes laborales portuarlos}

La capacidad de los industriales de utilizar insumos, fábricas e instalaciones de ensamblaje en distintas partes del mundo significa que pueden crear ventajas competitivas controlando el suministro, costo y calidad de las materias primas, reduciendo los costos de mano de obra, consiguiendo a trabajadores con las calificaciones necesarias, mejorando la eficiencia de la producción y distribución y colocándose en posición de ingresar a los mercados finales (Baker, 1994, pp. 106 y 108). Esto significa que la mano de obra portuaria es un insumo de los procesos de producción, así como la materia prima y la mano de obra industrial, y está expuesta a la competencia y a los estándares de desempeño del mercado laboral internacional. Los gobiemos deberían asegurarse de que para los estibadores, tales estándares no dimanen de medidas como sistemas de registro, monopolios de manipulación de carga y subvenciones oficiales, sino de respuestas a las señales del mercado que surgen de las necesidades de los usuarios. La reforma de los regímenes laborales portuarios basada en el mercado debe fomentar una nueva era de relaciones obrero-patronales basada en el respeto mutuo, la comunicación abierta, la participación en la adopción de decisiones y las obligaciones conjuntas en las áreas de productividad, control de los costos e innovación (Swoboda, 1993, p. C3; Bluestone y Bluestone, 1992, pp. 5-8 y 17-19).

No debe permitirse que los empresarios del transporte marítimo despidan trabajadores sin causa justificada, pasen por alto las disposiciones de los regíme- nes laborales y convenios colectivos o concierten con otros empleadores la no contratación de los trabajadores despedidos o la limitación de los aumentos de sueldos y prestaciones. Por ejemplo, algunos empleadores de la región de la CEPAL han establecido la práctica de no responder sencillamente a las demandas de los trabajadores para negociar colectivamente dentro de determinado plazo, para dar la impresión de indiferencia e inflexibilidad de su parte (Abrams y Trischwell, 1994, p. 1B; De Paula Leite, 1993, pp. 94-103; Bluestone y Bluestone, 1992, p. 202; Piniera, 1990, p. 134). No debe permitirse que los trabajadores portuarios perturben las actividades de manipulación de la carga, trabajen lento, dejen de trabajar durante la vigencia de un convenio colectivo, eviten cumplir con las disposiciones de los regímenes laborales nacionales que exigen la suspensión de huelgas, limiten la creación de otros sindicatos en el mismo lugar de trabajo, eludan la elección directa y secreta de sus directivos, ejerzan un control monopolístico sobre los servicios de manipulación y almacenamiento de la carga, y pongan límites a la utilización de tecnologías avanzadas de manipulación de carga o a la selección de estibadores.

En el nivel práctico de las operaciones de manipulación de la carga, la reforma laboral portuaria significa que los estibadores deben adquirir nuevas destrezas y aceptar nuevas prácticas operacionales. Los riesgos que conlleva la reformulación de los regímenes laborales consisten en que cada miembro de la comunidad portuaria y comercial se opondrá a distintos aspectos de cada modificación. Los empresarios del transporte marítimo quizá se opongan a un entorno competitivo abierto porque eliminaría la rentabilidad garantizada de sus inversiones y se verían obligados a hacer contribuciones para financiar programas de capacitación; los obreros portuarios podrían mostrarse igualmente renuentes porque tendrían que hacer frente a la inseguridad en materia de trabajo, salarios y prestaciones, y los gobiernos podrían considerar que tal entorno provocaría desencanto en el electorado. El equilibrio de estos factores con el parámetro externo de los mecanismos del mercado debería garantizar que los usuarios tengan la oportunidad comercial de lograr sus objetivos. Dado que estos cambios son muy amplios, sólo en la medida en que los gobiernos puedan aislar a los legisladores de la influencia de los trabajadores portuarios y de los empresarios del transporte marítimo, y viceversa, podrán estos factores incorporarse en los regímenes laborales portuarios basados en el mercado. 


\section{Negociaciones colectivas}

Los convenios que regulan la relación entre los empresarios del transporte marítimo y la fuerza laboral portuaria durante determinado lapso se formulan mediante negociaciones colectivas. Como se exigía un bajo nivel de especialización a los trabajadores portuarios, se los reemplazaba fácilmente, lo que creaba un desequilibrio en el poder de negociación entre ellos y sus empleadores (Edwards, 1993, pp. 13 y 14; Matos Mar, 1988, pp. 309-352; Brezzo y Vispo, 1988, pp. 413-443). ${ }^{6}$ Los gobiernos comenzaron a participar en esas negociaciones para equilibrarlas, administrar y validar los acuerdos consiguientes y resolver controversias (Díaz Corvalán, 1993, pp. 114-121; Solimano, 1988, pp. 135-158). Sin embargo, la falta de una base imparcial para estimar las demandas de la mano de obra portuaria y la posición de los empresarios del transporte marítimo provocan enfrentamientos en las negociaciones colectivas, debido a que los trabajadores consideran los temas desde una perspectiva social, en tanto que los empleadores los perciben desde una dimensión comercial y los gobiernos los utilizan como medio de redistribuir la riqueza nacional y hacer realidad sus propias aspiraciones políticas. Durante decenios se ha recurrido a los monopolios de manipulación de la carga, los sistemas de registro de estibadores y las subvenciones oficiales para salvar la diferencia entre las metas comerciales, sociales y políticas, pero la competitividad de una economía globalizada exige que sean reemplazados por mecanismos del mercado.

La injerencia directa del gobierno en las negociaciones colectivas se ha vuelto impracticable debido a que la competencia en una economía mundial intensifica las diferencias entre las metas comerciales, políticas y sociales y limita los medios que pueden utilizar los gobiernos para conciliarlas. El régimen laboral reformado eliminaría el sector público como participante directo en las negociaciones colectivas y lo reemplazaría por los mecanismos del mercado. Los objetivos de equilibrar los intereses de las partes negociadoras, motivar a los trabajadores portuarios y evitar presiones políticas pueden lograrse

\footnotetext{
6 Esto refleja también uno de los postulados más antiguos y fundamentales de la Organización internacional del Trabajo: la adopción de diversos convenios y recomendaciones que establecen normas laborales internacionales en las conferencias internacionales del trabajo de carácter tripartito (gobiernos, directivos empresariales y movimientos laborales). Véase olT, 1983, p. 10.
}

mediante un marco regulador que exponga a las partes negociadoras a los mecanismos del mercado y asegure que éstos se utilicen solamente para competir. En este contexto, las negociaciones colectivas pueden contribuir de manera positiva a la productividad y eficacia en función de los costos de la mano de obra portuaria. Al entablar negociaciones colectivas, los gobiemos, los empresarios del transporte marítimo y los sindicatos portuarios no deben tener recelo los unos de los otros o temer que no podrán alcanzar sus respectivas metas; el principal temor debe ser la creación de un puerto que carezca de atractivo comercial para los usuarios y que no pueda competir en una economía mundial.

\section{El movimiento sindical portuario}

En la región de la CEPAL el movimiento sindical ha venido perdiendo miembros y actualmente su supervivencia es motivo de preocupación; por ejemplo, la proporción de trabajadores afiliados a sindicatos en Chile se redujo de $33.7 \%$ de la fuerza de trabajo en 1973 a $11.2 \%$ en 1985 , aunque recientemente aumentó a $13.7 \%$ en 1994 (ILADES, 1995, pp. 1-4). Como estas cifras reflejan una tendencia que se está registrando en muchos otros países, el movimiento sindical portuario debe generar ideas para aumentar la productividad y controlar los costos, y demostrar a los usuarios y empresarios del transporte marítimo que su futuro comercial depende de los estibadores sindicalizados. Las demandas sindicales ya no pueden seguir formulándose fuera del marco comercial a que hacen frente usuarios y empresarios del transporte marítimo. El colectivismo social del movimiento laboral portuario como razón organizadora de los trabajadores se pondrá cada vez más en tela de juicio en el escenario laboral sumamente individualista de los puertos modernos, pero no así la necesidad de contar con un centro de coordinación de los trabajadores y empresarios del transporte marítimo para que respondan a la competencia de otros puertos y terminales (Bluestone y Bluestone, 1992, pp. 150-152). Si se desea que el movimiento sindical portuario redefina su papel en la economía mundial, es preciso que fortalezca su influencia en cuestiones comerciales con los empresarios del transporte marítimo para salvaguardar sus propios puestos de trabajo, ingresos y prestaciones (The Economist, 1993b, pp. 37 y 38, 1993 d, p. 40 y 1993 c, p. 102 ).

Los intereses creados del movimiento laboral portuario, de los gobiernos y de los partidos políticos en 
los regímenes laborales portuarios existentes representan las fuentes de resistencia a su revisión basada en el mercado. Las presiones competitivas que surgen debido a la emergencia de una economía globalizada, la introducción de metas de crecimiento inducido por las exportaciones y la utilización de tecnologías modernas de información y manipulación de la carga deberían eliminar tal resistencia si se termina con los sistemas de registro, los monopolios de la manipulación de carga y las subvenciones estatales y se los reemplaza por los mecanismos del mercado; si se liberalizan y descentralizan las negociaciones colectivas y el mercado laboral portuario; si se permite que los intereses privados inviertan y operen en los puertos del sector público, y si la mano de obra portuaria y los empresarios del transporte marítimo colaboran para aumentar la productividad y reducir los costos. Con el cambio a sistemas con uso intensivo de capital, los estibadores se han convertido en especialistas altamente calificados y el movimiento sindical portuario debería proponer que fueran objeto de un trato más personalizado en materia de sueldos, pensiones, prestaciones de salud, seguro de vida, programas de capacitación, objetivos de carrera y vacaciones, a fin de dar a cada trabajador un incentivo para superarse y mejorar su contribución al eficiente funcionamiento portuario (The Nikkei Weekly, 1994, p. 12; Heldman, Bennett y Johnson, 1981, pp. 135 y 136).

Los dirigentes sindicales deben contar con la confianza de los afiliados para llevar adelante la formidable tarea de transformar a los sindicatos de instituciones sociopolíticas en organizaciones sociocomerciales. Por ejemplo, la Asociación Latinoamericana de Servicios de Transporte Marítimo, que es una conferencia de líneas regulares, informó a la administración portuaria del puerto centroamericano de Santo Tomás de Castilla (Guatemala) que impondría una sobretasa de 200 dólares para protegerse contra robos si no se ponía coto a la elevada incidencia de hurtos de carga (International Transport Journal, 1994, p. 2837). Los dirigentes sindicales de ese puerto se percataron de que no contaban con respaldo cuando sugirieron a los afiliados en una reunión que había algunos de ellos que no debían ser aceptados porque simulaban enfermedad y se dedicaban a hurtar la carga. Así como se elige a los parlamentarios para que sean agentes del cambio, igual cosa sucede con los dirigentes sindicales, pero a menudo éstos se transforman en defensores del statu quo a fin de asegurarse la reelección (Curtis, 1994, pp. 34, 35 y 37). Ambos tienden a eludir decisiones que puedan significarles pérdida de votos y tratan de obtener dividendos políticos criticando innovaciones impopulares pero sensatas. Los dirigentes sindicales no pueden ser renuentes a hacer cumplir la disciplina comercial a sus afiliados, si ella origina aumentos de productividad y reducción de costos, ni a poner en evidencia a los grupos de trabajadores que utilizan los puertos para su enriquecimiento personal.

\section{Los empresarios del transporte marítlmo}

Los empresarios del transporte marítimo pueden hacer el mayor beneficio a los usuarios cuando se guían por una profunda comprensión o visión estratégica del mercado, los servicios y las fuerzas tecnológicas y jurídicas que transforman continuamente el funcionamiento de los puertos. Esto les permitirá prever las necesidades de los usuarios, ajustarse al cambio, efectuar inversiones y seleccionar, capacitar y motivar a los estibadores, y señalará las características de los empresarios del transporte marítimo exitosos en una economía mundial altamente competitiva. Es decir, los empresarios del transporte marítimo tienen que valorar a los trabajadores especializados, estar dispuestos a compartir la autoridad decisoria en el lugar de trabajo, y hacer sacrificios para retenerlos y readiestrarlos, en tanto que los estibadores deben ofrecer servicios novedosos, productivos y eficaces en función de los costos, y estar dispuestos a aceptar cambios en sus funciones que respondan a las necesidades de los usuarios (Watts, 1984, p. 34). Los empresarios del transporte marítimo no pueden funcionar como si fueran parte de una burocracia gubernamental y aislarse de las realidades comerciales que enfrentan los usuarios. Al hacer frente a un mercado globalmente competitivo, deben aprovechar mejor su tiempo y dinero, ya que dispondrán menos de ambos para efectuar inversiones, capacitar a estibadores y proporcionar servicios eficaces en función de los costos. Por último, los empresarios del transporte marítimo deben tratar de alentar a los estibadores a que desarrollen una predisposición a mejorar progresivamente la productividad y el control de los costos. 


\section{V \\ Consecuencias de la reforma laboral portuaria}

Una economía globalizada limita la capacidad de los gobiernos de adoptar medidas en virtud de las cuales se concedan derechos a la fuerza laboral. si éstos perjudican el atractivo comercial de un puerto o la competitividad de los bienes y servicios de los usuarios en los mercados internacionales o se traducen en la creación de monopolios. Así como el capital y la mano de obra son dos caras de la misma moneda, también lo son la participación privada en los puertos estatales y la reforma laboral portuaria basada en el mercado. La participación privada en los puertos estatales pone de relieve la necesidad de aplicar la reforma, y ésta garantiza que se puedan lograr las metas de los empresarios privados. Sin un régimen laboral portuario orientado hacia el mercado, no se podrá establecer una base comercial para la participación privada; sin participación privada, el movimiento laboral portuario tendrá pocos incentivos para aceptar una reforma de su régimen regulador basada en el mercado.

\section{Consecuenclas de carácter económico}

La aprobación de regímenes laborales orientados hacia el mercado garantizará que los estibadores tengan en cuenta en sus demandas los objetivos de crecimiento de la nación basados en las exportaciones, la competencia que enfrentan los usuarios y las necesidades del mercado laboral internacional en términos de costo y productividad. Los estibadores pueden hallarse en una posición de monopolio en un determinado puerto, pero forman parte de la economía mundial y se han visto ineludiblemente arrastrados al mercado laboral internacional, por lo que están obligados a competir con sus homólogos del otro lado del océano si manipulan mercaderías comparables destinadas a los mismos mercados (Reich, 1992 , pp. 120-122). Los estibadores estarán motivados para responder a las necesidades de los usuarios a fin de conservar sus propios ingresos y puestos de trabajo (Vernon-Wortzel y Wortzel, 1988, pp. 27-35). Así pues, los puertos sufrirán una transformación y pasarán de lugares donde los gobiernos dan prioridad a los salarios y prestaciones de los estibadores a lugares donde la fuerza laboral portuaria dará prefe- rencia a los objetivos comerciales de los usuarios. Las naciones que cedan ante las presiones de los sindicatos portuarios y no reformen los regímenes laborales perderán oportunidades claves para obtener ventajas competitivas para sus productos en los mercados internacionales.

En una economía mundial, las fronteras comerciales convencionales se expandirán. Los mercados, productores, objetivos laborales y objetivos estratégicos nacionales no ocupan ya la posición predominante que una vez tuvieron, porque han comenzado a emerger del recinto cerrado de una economía política. Con la puesta en marcha de regímenes laborales portuarios orientados hacia el mercado, los estibadores estarán expuestos a las fuerzas del mercado laboral internacional y los empresarios del transporte marítimo no tendrán que pagarles por el valor político de sus servicios. Pagarán los salarios que determine el mercado: ni más, ni menos (Suárez, 1994, p. A2; Standing, 1992, pp. 327-354). Esto permitírá que los empresarios del transporte marítimo y la fuerza laboral portuaria satisfagan las necesidades de los usuarios mediante una mayor productividad, en vez de la protección del mercado y subsidios del gobierno. En un estudio efectuado por la CEPAL sobre la reforma de la legislación laboral portuaria en Chile se estima la distribución del ahorro entre los usuarios y la autoridad portuaria del sector público, sobre la base de una comparación de los recursos empleados en 1980 y $1986 .^{7}$ En el cuadro 2 se demuestra que el ahorro real de que disfrutaron los usuarios es considerable.

Los empresarios del transporte marítimo y la fuerza laboral portuaria se interesarán en el costo y la productividad de sus actividades recíprocas, porque su viabilidad comercial en una economía mundial se relaciona con el valor que cada una de las partes agrega o sustrae a los productos. Por ejemplo, en 1982 los usuarios de los puertos chilenos se beneficiaron con un ahorro anual de 40 millones de dólares como consecuencia de la reforma de la legislación

\footnotetext{
7 CEPAL, 1989, pp. 36-41. Respecto de los puertos franceses, véase Containerisation International, 1993, p. 25, “...as Marseilles pacifies".
} 
CUADRO 2

Chile: Distribución estimada del ahorro después

de la liberalización en el ámblto comercial portuario

\begin{tabular}{|c|c|c|c|c|}
\hline \multirow[t]{2}{*}{ Producto } & \multirow[t]{2}{*}{ Unidad } & \multicolumn{3}{|c|}{ Ahorro } \\
\hline & & $\begin{array}{l}\text { Duet̃o de la carga } \\
\text { o del barco }\end{array}$ & EMPORCHI & Total \\
\hline Frutas & Dólares por caja & 0.14 & 0.14 & 0.28 \\
\hline Barras de cobre & Dólares por tonelada & 6.70 & -4.05 & 2.66 \\
\hline $\begin{array}{l}\text { Harina de pescado } \\
\text { en sacos }\end{array}$ & Dólares por tonejada & 4.61 & 1.57 & 618 \\
\hline Madera aserrada & Dólares por $\mathrm{m}^{3}$ & 2.81 & 1.63 & 4.44 \\
\hline Troncos & Dólares por $\mathrm{m}^{3}$ & 2.73 & 0.63 & 3.36 \\
\hline $\begin{array}{l}\text { Carga fraccionada } \\
\text { jmportada }\end{array}$ & Dólares por tonelada & 3.55 & 3.22 & 6.77 \\
\hline
\end{tabular}

Fuente: Ingenieros y Economistas Consultores Lida. (INECOL).

" El signo negativo indica pérdidas.

laboral de 1981, y para 1993 tal ahorro había superado los 118 millones de dólares; esto significó un descenso respecto del año anterior, en que se había registrado un ahorro de 121 millones de dólares (Cámara Marítima de Chile, A.G., 1993, p. 26, y 1992, p. 28). Ello llevará a una integración más estrecha entre usuarios, empresarios del transporte marítimo y estibadores, y obligará a quienes prestan servicios portuarios a responder rápidamente a los cambios en la demanda de bienes, rutas y tecnologías. Los estibadores y los empresarios del transporte marítimo buscarán conjuntamente la manera de mejorar la eficiencia de los servicios de manipulación de la carga y aumentar los salarios, prestaciones y seguridad en el empleo de la fuerza laboral portuaria porque persiguen el mismo objetivo económico: que los puertos tengan mayor atractivo comercial para los usuarios.

\section{Consecuencias de carácter político}

La consecuencia política más saliente de la reforma laboral sería que los gobiernos se retiraran de la participación directa en las relaciones laborales portuarias, salvo como reguladores, propietarios e inversionistas promocionales. Ello no debería provocar abusos, dado que el parámetro externo común de los mecanismos del mercado reemplaza a los gobiemos. Las funciones reguladoras se limitarían a establecer, reforzar y proteger la competencia, así como a resolver formalmente las controversias. El éxito comercial ya no provendrá de alianzas políticas, sistemas de registro de estibadores, monopolios de manipulación de la carga y subvenciones oficiales, sino de la posibilidad de movilizar los factores de producción a nivel mundial para estructurar una combinación viable de productos y servicios que pueda competir en los exigentes mercados internacionales. Los regímenes laborales portuarios orientados hacia el mercado requieren que los gobiemos estén conscientes de los mecanismos del mercado y comprendan lo que significan para los estibadores y empresarios del transporte marítimo, y que protejan a los legisladores de las presiones ejercidas por los grupos dominantes. Tal estructura transformará a los sindicatos: de actores políticos que se sirven de los procedimientos gubernamentales para beneficio exclusivo de sus afiliados se convertirán en novedosas "empresas mixtas" con los empresarios del transporte marítimo, en que se ayudarán a sí mismos a mejorar sus salarios, prestaciones y seguridad en el empleo, y a los usuarios a alcanzar los objetivos comerciales.

\section{Consecuencias de carácter social}

La economía mundial altamente competitiva en la que se hallan inmersos los puertos no permite que los gobiemos impongan programas sociales a los empresarios del transporte marítimo sin tener en cuenta el entorno comercial que enfrentan los usuarios. La participación del sector privado en los servicios y la última palabra en instalaciones constituyen una condición necesaria para alcanzar los objetivos comerciales, pero son insuficientes sin una fuerza laboral bien capacitada, altamente productiva y eficaz en función de los costos. Dado que el éxito comercial de los empresarios del transporte marítimo se relaciona estrecha- 
mente con el trabajo arduo, la lealtad y las habilidades de los estibadores, los recursos humanos tienen un papel decisivo en la creación de servicios portuarios atractivos para los usuarios. Los empresarios del transporte marítimo deberían reconocer que los objetivos comerciales están entrelazados con las metas sociales de los estibadores, y que ninguno de ellos puede lograrse en forma independiente. Así pues, existe una base social del éxito comercial que obliga a los empresarios del transporte marítimo a ir más allá de la eficiencia y los ingresos de las empresas para capacitar y motivar a los empleados, fomentar la lealtad, colaborar con ellos y asegurar su bienestar.

Las consecuencias en el más largo plazo de la interdependencia entre los objetivos comerciales y sociales son que los empresarios del transporte marítimo y la fuerza laboral portuaria tratarán de evitar la intensificación de sus controversias en los sistemas confrontacionales de arbitraje y tribunales, porque trabajarán juntos para alcanzar objetivos orientados al consenso que exigen elementos intangibles, como los mejores esfuerzos dinámicos y la buena voluntad de ambas partes (Cabot, 1986, pp. 14 y 15). Un desplazamiento de las relaciones laborales desde la confrontación hacia la búsqueda de objetivos comunes se traducirá en una mayor conciencia comercial de parte de la fuerza laboral portuaria y una mayor conciencia social de parte de los empresarios del transporte marítimo. La "cuestión social" expresada al comienzo del presente siglo respecto de los estibadores se ampliará e incluirá una "cuestión competitiva". La determinación de sì los sindicatos portuarios y los empresarios del transporte marítimo aceptan Ja cuestión competitiva y los valores compartidos y responden a ellos no depende de su buena voluntad, sino de los recursos políticos que poseen los gobiernos para formular un marco institucional que asegure que ambos se sometan a los mecanismos del mercado. En adelante los estibadores prometerán lealtad a los usuarios y empresarios del transporte marítimo, y no a funcionarios elegidos o designados, de manera que las instalaciones y el terminal portuarios tengan atractivo comercial y ellos puedan mejorar sus propios salarios y prestaciones.

\section{VI}

\section{Conclusiones y recomendaciones}

Es casi imposible imaginarse al movimiento sindical portuario en una situación más difícil: ha sido incapaz de proponer un plan que ayude a los estibadores a pasar de un marco monopolístico a uno competitivo; los adelantos técnicos están disminuyendo la demanda de estibadores, haciéndolos más productivos y obligando a los que quedan a actualizar sus habilidades; las políticas de crecimiento basado en las exportaciones los han expuesto a la competencia sin fronteras de una economía mundial; ha disminuido la eficacia de las alianzas políticas, los sistemas de registro de estibadores, los monopolios en materia de manipulación y almacenamiento de la carga y las subvenciones oficiales; hay una creciente desilusión con el movimiento sindical, ya que los trabajadores parecen alejarse de un enfoque colectivista en favor de cierta forma de autonomía protegida; y los gobiernos han comenzado a adoptar las primeras medidas para sentar las bases de la participación privada en los servicios e instalaciones porturarios.

\section{Nuevas funciones de los gobiernos}

Los gobiemos deben utilizar los elementos constitutivos de los regímenes laborales portuarios sensibles al mercado para alcanzar los objetivos comerciales y las metas sociales orientadas hacia las oportunidades. Deben eliminar de las relaciones laborales portuarias su propia participación directa, así como la de los partidos políticos, organizaciones internacionales, sindicatos extranjeros, universidades, fuerzas armadas y familiares de los estibadores, como medio de evitar presiones que tratan de modificar los resultados del mercado. Deben velar por que los regímenes laborales reformados permitan que los mecanismos del mercado generen oportunidades comerciales para los usuarios y los empresarios del transporte marítimo, así como la asignación de labores más satisfactorias y flexibles y mayores beneficios para los estibadores. La tarea a que se enfrentan los gobiernos no es solamente la eliminación de registros, monopolios, subsidios y alianzas, porque siempre existirá alguna mane- 
ra de restablecerlos, sino la creación de un marco institucional que utilice los mecanismos del mercado para conciliar los intereses de los empresarios del transporte marítimo y de los trabajadores portuarios en provecho de los usuarios, y aproveche la inteligencia de los estibadores y su capacidad de resolver problemas para mejorar la competitividad de la empresa. Los gobiernos no están sujetos a los mecanismos del mercado, pero tampoco están aislados de las realidades comerciales que enfrentan los usuarios y empresarios del transporte marítimo.

Los gobiernos deben adoptar un régimen laboral portuario en virtud del cual se liberalice la oferta y demanda de la mano de obra portuaria, se descentralicen las negociaciones colectivas al nivel de los distintos empresarios del transporte marítimo y se utilicen leyes antimonopolio para eliminar los límites a la competencia, de manera que las demandas de los usuarios, empresarios del transporte marítimo y trabajadores portuarios sean equilibradas y armonizadas por los mecanismos del mercado. Estas tareas constituyen una empresa casi totalmente política, pero corresponde a los gobiernos velar por que las metas comerciales y sociales se traten en un pie de igualdad y no se utilicen los procesos políticos para obstaculizar o distorsionar su realización. Con la incorporación de los factores nacionales de producción en los mercados mundiales, la colaboración entre los empresarios del transporte marítimo y los trabajadores portuarios será fundamental para la viabilidad comercial y la seguridad laboral. Los gobiernos deben velar por que los regímenes laborales portuarios reformados conjuguen los intereses de la fuerza laboral portuaria y de los empresarios del transporte marítimo mediante el establecimiento de obligaciones conjuntas respecto de la productividad, el control de los costos, la capacitación y el aumento de las perspectivas de carrera, con lo que se fomentará la colaboración y se sentarán las bases para conciliar las metas comerciales y sociales. Los gobiernos son responsables de la atmósfera sociopolítica en los puertos y sobre ellos recae la obligación de ayudar a los estibadores a cambiar de un entorno monopolístico a uno competitivo.

\section{Un régimen laboral portuario basado en el mercado}

Durante la era de los regímenes laborales portuarios paternalistas, los sindicatos tenían una orientación sociopolítica basada en la doctrina del "mejoramiento social mediante el trabajo" y constituían una fuerza importante en la política nacional. Sin embargo, la fortaleza del movimiento sindical portuario en la actualidad depende cada vez más de la capacidad de los trabajadores portuarios de agregar valor a los bienes y servicios de los usuarios y rentabilidad a las actividades de sus empleadores. La doctrina del "mejoramiento social mediante el comercio" no logrará mayor éxito que su homóloga anterior, a menos que los trabajadores portuarios y los empresarios del transporte marítimo sean expuestos a los mecanismos del mercado. No hay nada intrínsecamente malo en que haya peluqueros que corten el pelo a los estibadores y autobuses que los transporten entre sus hogares y los puertos, así como en que se exija que los empleadores contraten a los hijos de los estibadores que se retiran y se proporcionen instalaciones de recreación para los trabajadores portuarios, sistemas de registro, subvenciones estatales, salarios mínimos y semanas de trabajo garantizadas, prestaciones de desempleo y programas de jubilación y salud, salvo que todo esto lo obtuvo el movimiento sindical portuario fuera de los límites comerciales establecidos por los mecanismos del mercado.

Los sindicatos portuarios argumentarán que el hecho de someter estas conquistas sociales a los mecanismos del mercado tendrá graves consecuencias, como por ejemplo la supresión masiva de puestos y la autorización para que los empresarios del transporte marítimo se valgan del nuevo énfasis en las metas comerciales para incrementar sus ganancias a expensas de los trabajadores portuarios. Nada más lejos de la verdad si se produce la liberalización y descentralización por igual de la fuerza laboral portuaria y de los empresarios del transporte marítimo, se los somete a las leyes antimonopolio y se los respalda con programas de indemnización y readiestramiento. Con la complejidad técnica cada vez mayor de las operaciones de manipulación de la carga y la utilización de la equidad social orientada hacia la oportunidad para que los estibadores desplazados dispongan de programas de indemnización y readiestramiento, los gobiernos no tienen razón legítima alguna para demorar sus esfuerzos tendientes a estructurar regímenes laborales portuarios de mercado. Sin embargo, lo que los gobiernos hacen es introducir cambios basados en el consenso $\mathrm{y}$, sin este factor, la posibilidad de perder los votos de los estibadores que se sientan defraudados por su actuación fácilmente podría opacar la conveniencia de alcanzar objetivos comerciales y sociales.

La elaboración de regímenes laborales portuarios de mercado exige que los gobiernos actúen de 
manera transparente e imparcial, posean la capacidad de trascender los sueños utópicos y los hábitos monopolísticos para que los objetivos comerciales y sociales sean expuestos a los mecanismos del mercado, y organicen a toda la comunidad portuaria para que participe en el proceso. Las directrices para la solución informal de controversias elaboradas por los gobiernos brindan a los dirigentes sindicales portuarios y a los empresarios del transporte marítimo la oportunidad de ir más allá de la negociación de salarios y prestaciones y de colaborar mutuamente en la búsqueda de estructuras organizacionales, prácticas laborales y tecnologías alternativas que podrían utilizarse para alcanzar los objetivos comerciales y sociales. Para que el marco institucional reformado sea viable, debe dar a los empresarios del transporte marítimo la suficiente flexibilidad para seleccionar a los trabajadores más idoneos, asignar tareas y ofrecer los programas de capacitación que correspondan, a fin de satisfacer las necesidades de los usuarios. Será preciso actualizar con frecuencia ese marco para adaptarlo a las cambiantes condiciones del mercado y vigilarlo para asegurar que se cumplan sus disposiciones. Esto puede lograrse muy fácilmente mediante la creación de una comisión adscrita al ministerio del trabajo que deberá consultar con la comunidad portuaria respecto de las modificaciones al marco institucional que puedan mejorar la productividad y la efícacia en función de los costos.

\section{Estrategia de aplicación}

Los sindicatos portuarios tratarán de conservar los puestos de trabajo y salvaguardar los salarios y prestaciones de sus afiliados a través de medidas sociopolíticas. Los empresarios del transporte marítimo tratarán de obtener flexibilidad para contratar y despedir trabajadores, modificar la delimitación de las tareas y variar los salarios y prestaciones según la experiencia y productividad de los trabajadores, así como la realización de cursos de capacitación, a fín de asegurar que los usuarios se interesen en utilizar las instalaciones portuarias. Para conciliar estos objetivos contrapuestos, los gobiernos deberán elaborar estrategias de ejecución que den a los trabajadores portuarios una sensación de apoyo mutuo, la comprensión de que el cambio es inevitable, un esbozo de las funciones que desempeñarán durante y después del cambio, y la confianza de que se harán inversiones para su bienestar. Los trabajadores portuarios no aceptarán fácilmente la pérdida de puestos y prerrogativas, de modo que los gobiernos deben hacer públicos los criterios de selección de los funcionarios que pasarán a ser superfluos y los que pueden asistir a programas de readiestramiento, y un plan simplificado que permita a los trabajadores portuarios calcular sus prestaciones en materia de indemnización y jubilación.

Los gobiemos deberían constituir equipos integrados por funcionarios de los ministerios de hacienda, comercio, transporte, obras públicas y trabajo, así como de grupos de usuarios, sindicatos portuarios, empresarios del transporte marítimo y administraciones portuarias, para elaborar una legislación laboral portuaria basada en el mercado y la consiguiente estrategia de aplicación. Las actividades de esos equipos sembrarán la incertidumbre entre los estibadores y llevarán a los sindicatos a reclamar que los costos sociales son prohibitivos. Para responder a tal afirmación, será preciso que los equipos, usuarios y empresarios del transporte marítimo aúnen fuerzas para preparar estudios que demuestren que esa reforma es una exigencia de la economía mundial, que los objetivos comerciales y sociales pueden conciliarse sometiéndolos a la norma externa común de los mecanismos del mercado y que están dispuestos a compartir los inconvenientes y las ventajas de los nuevos regímenes laborales con los trabajadores portuarios a través de programas de indemnización, readiestramiento y jubilación. Estas medidas constituyen la respuesta humana o la equidad social compensatoria de una estrategia de ejecución de la reforma laboral portuaria y deberían invalidar las afirmaciones de que los nuevos regímenes suponen elevados costos sociales, que los trabajadores portuarios son los que soportan todo el peso del ajuste y que los problemas laborales portuarios no se han resuelto, sino que sencillamente se han trasladado a otro sector de la economía.

(Traducido del inglés) 


\section{Bibliografía}

Abrams, A. (1994a): Pressure is on labor for cuts, The Joumal of Commerce, Nueva York/New Jersey, Special Report, 12 de septiembre.

(1994b): Meeting may yield Philadelphia Deal, JLA chief says The Joumal of Commence. Special Report, 12 de enero.

Abrams. A. y P. Tirschwell (1994): NY Port auto handlers strike as pact expires, The Joumal of Commerce, Nueva York New Jersey, 2 de septiembre.

América Economia (1993): Amigos en Filadelfia, N 70 , Nueva York, World Financial Center, marzo.

Apolo, J.M. (1994): Los puertos y la modemizacion, Guayaquil, Famasa S.A.

Banuri, T. (1990): Comments of fields, S. Herzenberg y J.F. PérezLópez (eds.), Labor Standards and Development in the Global Economy, Washington, D.C., Depattamento del Trabajo de los Estados Unidos, Oficina de Asuntos Laborales lnternacionales.

Baker, S. (1994): The odd couple of steel, Business Week, Nueva York, Mc Graw-Hill Inc., 7 de noviembre.

Benedict, D. (1990): Gulf ports are vying for Latin America trade, Global Trade, junio.

Bluestone, B.e I. Bluestone (1992): Negoriating the future, Nueva York, Basic Books.

Brezzo. L.A. y J. Vispo (1988): Experiencia de la concertación de políticas de ingresos en Uruguay, Programa Regional del Enpleo para América Latina y el Caribe (PREALC), Politica económica y actores sociales, Ginebra, Organización Internacional del Trabajo (orT).

Cabot, S.J. (1986): Everybody Wins!, Nueva York, Hippocrene Books.

Cámara Marítima de Chile, A.G. (1992): Memoria anual de la Cámara Maríima de Chile, A.G., $\mathrm{N}^{\circ} 49$, Valparaíso.

(1993): Memoria antual de la Camara Maritima de Chile. A.G., $\mathrm{N}^{\circ} 50$, Valparaíso.

Cantwell, A. (1994): The Labor ties called key to ports' competitiveness. The Journal of Commerce, Nueva York/New Jersey 11 de octubre.

CEPAL (Comisión Económica para América Latina y el Caribe) (1989): La cadena de distribución y la competitividad de las exportaciones latinoamericanas. Racionalización portuaria en Chile, LC/G. 1597, Santiago de Chile, 29 de diciembre.

Compañía Guatemalteca de Terminales a Granel, S.A. (1988): Pacto colectivo de condiciones de trabajo, Ciudad de Guatemala.

Containerisation International (1993): ... as Marseilles pacifies, Londres, National Magazine Co. Ltd., diciembre.

Couper, A.D. (1986): New cargo-handling techniques: implications for port employment and skills, Ginebra, olT.

Curtis, J. (1994): Poised on the brink, Port Development Interna tional, Londres, octubre.

Davidow. W.H. y M.S. Malone (1992): The Virtuat Corporation, Nueva York, Harper Collins Publications.

Davies, J. (1993a): Labor board rejects doctors'appeal of staff reductions at grain terminal, The Joumal of Commerce, Nueva York New Jersey, 16 de noviembre.

(1993b): lLwU complaint against Peavey Grain dismissed. The Joumal of Commerce, Nueva York/New Jersey, 10 de septiembre.

De Paula Leite, M. (1993): Innovación tecnológica, organización del trabajo y relaciones industriales en et Brasil, Nueva sociedad, $\mathrm{N}^{\circ} 124$, Caracas, Editorial Texto, marzo-abril.

Díaz Corvalán, E. (1993): Nuevo sindicalismo, viejos problemas. La concertación en Chile, Nueva sociedad, $\mathbf{N}^{\circ} 124$, Caracas, Editorial Texto, marzo-abril.

Di Benedetto, W. (1991): Chilean fruit exporters, Phila. port make amends, The Joumal of Commerce, Nueva York/New Jersey, 6 de marzo.

(1994): ILWU president pushes "partnership" approach, The Journal of Commerce, Nueva York/New Jersey, 31 de octubre.

Eatwell, J., M. Milgate y P. Newman (eds.) (1987): The New Palgrave. A Dictionary of Economics, vol. 2, Londres, The Macmillan Press Led.

Edwards, R. (1993): Rights at Work: Employment Relations in the Post-Union Era, Washington, D.C., The Brookings Institution.

Fainplay. The International Shipping Weekly (1993): Hot competition for Chile cargoes, Londres, Fairplay Publications, 10 de junio.

(1994): Lines seek Santos congestion charge. Londres, Fairplay Publications, 10 de noviembre.

Finney, N. (1993): Putting right old port abuses, Lloyd's List, Londres, 7 de julio.

Handy, C. (1994): The Age of Paradox, Boston, Harvard Business School Press.

Heldman, D.C., J.T. Bennett y M.H. Johnson (1981): Deregulating Labor Relations, Dallas, Texas, The Fisher Institute.

Holcomb, H.J. (1993a): Philadelphia labor antagonist extends olive branch to ILA. The Journal of Commerce. Nueva York New Jersey, 27 de octubre.

(1993b): Philadelphia faces stiff challenge as premier winter fruit port in U.S., The Joturnal of Commerce, 27 de septiembre.

(1994a): Holt expands waterftont empire, buys stevedore firm, The Journal of Commerce, Nueva York/New Jersey, 23 de diciembre.

(19946): Port of Philadelphia sees threat in Wilmington, Del., fruit trade. The Joumal of Commerce. Nueva York/ New Jersey, 5 de diciembre.

ILADES (Instituto Latinoamericano de Doctrina y Estudios Sociales) (1995): Nuevas refomas laborales, Trabajo de Asesoría Económica al Congreso Nacional, Santiago de Chile, marzo.

International Transport Journal (1994): Guatemala: Theft surcharge?, $N^{\star}$ 36, Basilea, Rittmann Ltd., 9 de septiembre.

Johnston, D. (1993): Philadelphia seeks dock concessions as flow of fruit from Chile ebbs, The Joumal of Commerce, Nueva York/ New Jersey, 10 de junio.

Knox, A. (1991): Philadelphia dockers develop plan to keep fruit imports moving, The Journal of Commerce, Nueva York New Jersey, 4 de febrero.

Marshall, R. y M. Tucker (1992): Thinking for a Living: Education and the Wealth of Nations, Nueva York, Basic Books.

Matos Mar, J. (1988): Los interlocutores sociales y el proceso peruano de concertación, PREALC, Política económica y actores sociales, Ginebra, orr.

Mongelluzzo, B. (1994): ILwU. Undaunted by Peavey Case, hits other Conagra units, The Journal of Commerce. Nueva York/ New Jersey, 5 de febrero.

(1995): Long-simmering issues blamed for walkout, The Joumal of Commerce, Nueva York/New Jersey, $\mathrm{LI}$ de agosto.

Monk, F. (1995): Wilmington, N.C., expects Chilean fruit to surge, The Joumal of Commerce, Nueva York/New Jersey, 18 de enero.

OIT (1981): Participación de los trabajadores en las decisiones de la empresa, Ginebra.

(1983): Maritime labour conventions and recommendations, Ginebra.

Piñera, J. (1990): La revolución laboral en Chile, Santiago de Chile, Empresa Editora ZIG-ZAG.

Porter, M.E. (1991): La ventaja competitiva de las naciones, Buenos Aires, J, Vergara Editor, S.A. 
Reich, R.B. (1992): The Work of Nations, Nueva York, Vintage Books.

Ruiz-Tagle, J. (1991): Trabajo y economía en el retomo a la de. mocracia, Chile 1985-1991, Santiago de Chile, Programa de Economía del Trabajo (PET).

Schwieger, E.D. (1988): New concepts in dispute resolution, A.M. Glassamn, N. Berger Davidson y T.G. Cummings, Labor Relations: Reports from the Firing Line, Plano, Texas, Business Publications Inc..

Segura, J.F. (1993): The past, present and future of privatization, Latin Finance, suplemento titulado Corporate Finance in Lain America 1994, diciembre.

Solimano, A. (1988): Políticas macroeconómicas y reglas de formación de salarios, PREALC/OIT, Ginebra.

Standing, G. (1992): Do unions impede or accelerate structural adjustment? Industrial versus company unions in an industrialising labour market, Cambridge Journal of Economics, $N^{\circ}$ 3, vol. 16, Londres, Academic Press Ltd.

Suárez, R. (1994): Derecho laboral y economía, El Mercurio, Santiago de Chile, 10 de julio.

Swoboda, F. (1993): Reich urges labor-management peace, The Washington Post, Washington, D.C., 17 de marzo.
The Economist (1993a): A disappearing world, $N^{\circ} 7804$, Londres, 27 de marzo.

(1993b): The price of victory, Londres, 2 de octubre.

(1993c): Out! Out! Out!, Londres, 2 de octubre.

(1993d): The same old beast?, Londres, 2 de octubre.

The Joumal of Commerce (1993a): 1500 dockers protest at Peavey Grain terminal, 31 de agosto.

(1993b): In a reversal, Philadelphia dockers support cuts to keep jobs, 4 de octubre.

(1993c): Unifrutti to use N.C. port for Chilean fruit imports, 21 de octubre.

The Nikkei Weekly (1994): Firms test merit-based retirement plans in bid to spur employee efforts, vol. 32, Tokio, Nihon Keizai Shimbun, Inc., 28 de noviembre.

UNCTAD (Conferencia de las Naciones Unidas sobre Comercio y Desarrollo) (1993): Strategic Planning for Port Authorities, Ginebra, 29 de julio.

Vernon-Wortzel, H. y L.H. Wortzel (1988): Globalizing strategies for multinationals from developing countries. The Columbia Joumal of World Business, $\mathrm{N}^{\circ} 1$, vol. 23, Nueva York, the Trustees of Columbia University in the City of New York.

Watts, G. E. (1984): A rationale for employment security, Strategies for Productivity: Intemational Perspectives, Nueva York, UNIPUB. 